Phosphate defects and apatite inclusions in coral skeletal aragonite revealed by solid-state NMR spectroscopy

H. E. Mason, P. Montagna, L. Kubista, M. Taviani, M. McCulloch, B. L. Phillips

April 22, 2011

Geochemica et Cosmochimica Acta 
This document was prepared as an account of work sponsored by an agency of the United States government. Neither the United States government nor Lawrence Livermore National Security, LLC, nor any of their employees makes any warranty, expressed or implied, or assumes any legal liability or responsibility for the accuracy, completeness, or usefulness of any information, apparatus, product, or process disclosed, or represents that its use would not infringe privately owned rights. Reference herein to any specific commercial product, process, or service by trade name, trademark, manufacturer, or otherwise does not necessarily constitute or imply its endorsement, recommendation, or favoring by the United States government or Lawrence Livermore National Security, LLC. The views and opinions of authors expressed herein do not necessarily state or reflect those of the United States government or Lawrence Livermore National Security, LLC, and shall not be used for advertising or product endorsement purposes. 
Phosphate defects and apatite inclusions in coral skeletal aragonite revealed by solid-state

\section{NMR spectroscopy}

3 Harris E. Mason ${ }^{1 \dagger^{*}}$, Paolo Montagna ${ }^{2,3 \ddagger}$, Laura Kubista ${ }^{1}$, Marco Taviani $^{3}$, Malcolm McCulloch $^{4 \S}$,

4 Brian L. Phillips ${ }^{1}$

$5 \quad{ }^{1}$ Department of Geosciences, Stony Brook University, Stony Brook, New York 11794-2100

$6 \quad{ }^{2}$ Lamont-Doherty Earth Observatory Columbia University, 61 Route 9W, Palisades, NY 10964

$7 \quad{ }^{3}$ Istituto di Scienze Marine (ISMAR), Consiglio Nazionale delle Ricerche (CNR), Via P. Gobetti

8 101, 40122 Bologna, Italy

$9{ }^{4}$ Research School of Earth Sciences, Australian National University, Canberra, ACT 200,

10 Australia

11 * corresponding author email: mason42@1lnl.gov

†Present address: Physical Life Sciences Directorate, Lawrence Livermore National

Laboratory, Livermore, CA 94550, USA.

†Present address: Laboratoire des Sciences du Climat et 1'Environnement, Gif-sur-Yvette, 91198, France

${ }^{\S}$ Present address: University of Western Australia School of Earth and Environment Rm 138 M004 ARC Centre of Excellence in Coral Reef Studies

Crawley, Western Australia 6009

\section{Abstract}

22 Recent development of paleo-nutrient proxies based on the Phosphorus/Calcium $(\mathrm{P} / \mathrm{Ca})$ ratio in

23 tropical- and deep-water corals (also known as cold-water corals) illustrate the necessity for

24 understanding the processes by which $\mathrm{P}$ is incorporated into the coral skeletal aragonite. Here

25 we apply single- and double-resonance solid-state nuclear magnetic resonance (NMR)

26 spectroscopy to determine the speciation of $\mathrm{P}$ in coral aragonite. The results show that the

27 majority of $\mathrm{P}$ occurs as phosphate defects in the aragonite structure, but in many samples a

28 significant fraction of the $\mathrm{P}$ occurs also in crystalline hydroxylapatite inclusions. Quantification

29 of the amount of hydroxylapatite indicates that its presence is not related simply to external

30 environmental factors and that it can occur in varying abundance from different parts of the same

31 corallite. Since there is currently no model available to describe the relationship between 
32 dissolved inorganic phosphate and incorporation of apatite inclusions into carbonates, careful

33 screening of samples which contain only phosphate in the aragonite structure or selective

34 microsampling could improve proxy development.

35

36 Keywords: coral, phosphate, aragonite, NMR spectroscopy, apatite, ${ }^{31} \mathrm{P},{ }^{1} \mathrm{H},{ }^{19} \mathrm{~F}$ 


\section{INTRODUCTION}

It has been recently proposed that $\mathrm{P} / \mathrm{Ca}$ ratios in the aragonite skeleton of corals record

39 the concentration of ambient dissolved inorganic phosphorus (DIP), which, when combined with

40 U-series chronology, could prove to be a useful paleo-nutrient proxy (Montagna et al. 2006;

41 Anagnostou et al., 2007; LaVigne et al., 2008; LaVigne et al., 2010; Anagnostou et al., 2011).

42 The amount of bioavailable phosphate in the photic zone of the surface ocean serves as a limit to

43 primary productivity in some ocean basins. Since export of biomass to deep waters may act to

44 drawdown atmospheric $\mathrm{CO}_{2}$ (Broecker, 1982; Volk and Hoffert, 1985; Sarmiento et al., 1998),

45 knowledge of past oceanic $\mathrm{P}$ concentrations is important to estimate the contribution of the

46 "biological pump" to the levels of atmospheric $\mathrm{CO}_{2}$. Montagna et al. (2006) noted that laser

47 ablation inductively coupled plasma mass spectrometry (LA-ICPMS)-derived P/Ca ratios for

48 aragonite septa from a variety of recent Desmophyllum dianthus coral samples were linearly

49 related to the DIP concentration of the waters from which they were collected. This correlation

50 was used to reconstruct paleo-nutrient data from a $\sim 11190 \mathrm{yr}$ old sample. Unlike other trace

51 elements used as paleo-environmental proxies, such as $\mathrm{Ba}, \mathrm{Sr}$ and $\mathrm{Cd}, \mathrm{P}$ cannot substitute simply

52 into the aragonite crystal structure and its form in the coral aragonite is unknown (Dodge et al,

53 1984). The $\mathrm{P}$ speciation can be reasonably expected to influence the relationship between DIP

54 concentration and aragonite $\mathrm{P} / \mathrm{Ca}$.

55 Geochemical models of trace element incorporation in calcite and aragonite typically rely

56 on thermodynamic treatment of incorporation of the trace element into the mineral structure

57 (Cohen and McConnaughey, 2003; Gagnon et al., 2007; Gaetani and Cohen, 2006). Phosphate

58 co-precipitation, sorption, and desorption studies at phosphate solution concentrations less than

$59100 \mu \mathrm{M}$ and near neutral $\mathrm{pH}$ suggest that inorganic phosphate incorporation in calcite can be 
60 modeled by adsorption and subsequent incorporation of protonated phosphate groups (House and

61 Donaldson, 1986; Hinedi et al., 1992; Millero et al., 2001). It has also been shown in certain

62 cases that calcite with $60-100 \mu \mathrm{g} / \mathrm{g}$ P can contain crystalline Ca-phosphate inclusions that are

63 difficult to detect by microanalytical methods, suggesting that surface precipitates can form and

64 be subsequently encapsulated by continued crystal growth (Mason et al., 2007). Crystalline Ca-

65 phosphates can be difficult to nucleate and models that could account for the formation of such

66 P-rich precipitates via heterogeneous nucleation on calcium carbonate surfaces (Koutsoukos and

67 Nancollas, 1981) have yet to be fully explored. Therefore, to model the co-precipitation of

68 phosphate with calcium carbonate minerals it is desirable that phosphate is incorporated as a

69 structural constituent.

70 Solid-state ${ }^{31} \mathrm{P}$ nuclear magnetic resonance (NMR) spectroscopy is one potential

71 technique from which information on the distribution of $\mathrm{P}$ in coral aragonite might be obtained.

72 The ${ }^{31} \mathrm{P}$ NMR chemical shift is very sensitive to the bonding environment surrounding $\mathrm{P}$ and has

73 distinct, often characteristic values for crystalline phases. ${ }^{31} \mathrm{P}$ NMR techniques, primarily in the

74 liquid state, have been used extensively to determine P-speciation in soluble extracts from soil

75 samples and from marine sediments and particulate matter (for a review of these ${ }^{31} \mathrm{P}$ studies see

76 Cade-Menun, 2005, and Turner et al, 2005 for a review of extraction methods). Such methods

77 yield high resolution of organic P-species and are required for NMR investigation of materials

78 containing significant concentrations or paramagnetic ions (which cause severe linebroadening in

79 NMR spectra), but require harsh chemical treatments to separate various $\mathrm{P}$ fractions. In

80 addition, only a fraction of the $\mathrm{P}$ is extracted from the solids (typical recovery $30-60 \%$ ), with

81 some P remaining in the insoluble residue (Ahlgren et al, 2007). Considering that coral

82 aragonite typically contains low concentrations of $\mathrm{Fe}$ and $\mathrm{Mn}$, and bulk $\mathrm{P}$ concentrations just 
83 within the NMR detection limit, it might be amenable to investigation by in situ solid-state ${ }^{31} \mathrm{P}$

84 NMR methods.

85 Here we present a survey of solid-state ${ }^{31} \mathrm{P}$ NMR spectra of coral skeletal material that

86 illustrates the potential of the technique for determining the speciation of $\mathrm{P}$ in such materials, and

87 in other carbonate minerals as well. We use a variety of solid-state NMR spectroscopic methods

88 to characterize inorganic phosphate in a synthetic aragonite/phosphate coprecipitate and show

89 that the phosphate occurs within $3.2 \AA$ of several carbonate groups, indicating that it is

90 incorporated in the aragonite structure. The similarity of these data with those obtained for coral

91 skeletal material provides strong evidence that structural phosphate defects are the principal P-

92 species in coral aragonite. Many coral samples also yield a ${ }^{31} \mathrm{P}$ NMR signal characteristic of

93 crystalline apatite that can represent a significant fraction of the bulk $\mathrm{P}$, but the origin of which is

94 uncertain. These results support the use of $\mathrm{P} / \mathrm{Ca}$ ratios for paleo-environmental proxies, but also

95 suggest that the proxy relationships might be improved by selecting samples lacking apatite

96 inclusions.

97

98 2. EXPERIMENTAL METHODS

99 2.1. Sample Preparation

100 2.1.1. Coral Samples

101 Subsamples of coral skeleton were selected from modern and subfossil corals lacking any

102 visible Fe-Mn-rich crust, checked under a binocular microscope and using thin sections under

103 plane and cross-polarized light. No major visible alterations (e.g. diagenetic alteration or

104 bioerosions) were evident. The $\mathrm{P} / \mathrm{Ca}$ ratios and the $\mathrm{P}$ concentration for the coral samples were 
105 obtained using LA-ICPMS following the procedures of Montagna et al (2006) and through 106 solution ICPMS (see method below).

107 The sampling methods differed among the various coral species.

108 Desmophyllum dianthus and Flabellum sp.: fragments of the largest septum S1 were 109 carefully removed by a diamond tipped saw attached to a dentist drill. Other subsamples

110 were cut from the thecal wall and all the fragments of septa attached to the theca were 111 mechanically abraded away using the same dentist drill. This allowed us to obtain 112 samples representative of both the septum and the thecal margin. Two subsamples of 113 Desmophyllum dianthus septa were crushed to pass a $250 \mu \mathrm{m}$ analytical sieve and 114 subjected to chemical cleaning; one was placed in a bleach solution $(6 \% \mathrm{NaClO})$ and 115 agitated for four days and another was treated using a method similar to those prescribed 116 by Shen and Boyle (1988), Cheng et al (2000), and LaVigne et al. (2008) which are 117 designed to remove sorbed metals and metal oxide coatings.

118 Lophelia pertusa: pieces of the thecal wall were obtained by cutting single corallites 119 transversally. The part corresponding to the intersection between the wall and the septa 120 (inside edge of the theca) was abraded and septa were completely removed.

121 Madrepora oculata: a piece of the coral was collected by cutting a corallite transversally.

122 This coral portion contains both the thecal wall and the septa ("whole coral" reported in 123 the text).

124 Porites sp.: a small rectangular parallelepiped was removed from a $7 \mathrm{~mm}$ slab previously 125 obtained by cutting a coral core along the axis of growth. The subsample was taken at a 126 distance of $12 \mathrm{~cm}$ from the top of the coral core in order to avoid the remnants of coral 127 tissue. 


\subsubsection{Synthetic aragonite/phosphate coprecipitates}

Aragonite/phosphate co-precipitation was undertaken using a seeded constant addition

131 method adapted from Zhong and Mucci (1993) and described by Reeder et al. (2000). The

132 aragonite seeds were synthesized by pumping separate solutions of $0.2 \mathrm{M} \mathrm{CaCl}_{2}$ and $0.2 \mathrm{M}$

$133 \mathrm{Na}_{2} \mathrm{CO}_{3}$ using a dual syringe pump at a rate of $300 \mu \mathrm{l} / \mathrm{min}$ into a constantly stirring initial

134 solution containing $7 \mathrm{mM} \mathrm{CaCl}_{2}, 7 \mathrm{mM} \mathrm{NaHCO}$, and $50 \mathrm{mM} \mathrm{MgCl}_{2}$ which was being bubbled

135 with air. Each solution contained $0.1 \mathrm{M} \mathrm{NaCl}$ as background electrolyte. The aragonite seeds

136 were identified as pure aragonite by powder X-ray diffraction and analyzed by scanning electron

137 microscopy (SEM) to determine the average dimensions and morphology of the crystals,

138 revealing blocky crystals typically $3 \mu \mathrm{m}$ wide by 4 to $10 \mu \mathrm{m}$ long grouped into ball-shaped

139 clusters 40 to $50 \mu \mathrm{m}$ in diameter. For phosphate co-precipitation, the same procedure was used

140 except $0.1 \mathrm{~g}$ of aragonite seed material was added to the initial growth solution, the

141 concentrations of reactants in the syringes were $0.1 \mathrm{M}$, and $\mathrm{NaHPO}_{4}$ was added to the carbonate

142 syringe such that the phosphate concentration of the syringe ranged from 50 to $100 \mu \mathrm{M}$. A $0.1 \mathrm{M}$

$143 \mathrm{NaH}^{13} \mathrm{CO}_{3}$ solution replaced the $\mathrm{Na}_{2} \mathrm{CO}_{3}$ syringe to synthesize a ${ }^{13} \mathrm{C}$-enriched sample. This

144 sample was prepared for ${ }^{31} \mathrm{P} /{ }^{13} \mathrm{C}$ double resonance NMR experiments where the low (1.1\%)

145 natural abundance of the NMR active ${ }^{13} \mathrm{C}$ nucleus prevents observation of spectroscopic effects.

146 Periodically, solution was drawn from the growth solution to analyze total carbonate and reactive

147 phosphate concentrations, from which we determined that the phosphate concentration ranged

148 from 1 to $3 \mu \mathrm{M}$ during crystal growth. After 4 to $5 \mathrm{~h}$ of reaction time the solid was collected,

149 filtered, and dried for $2 \mathrm{hrs}$ in a $60^{\circ} \mathrm{C}$ oven. The $\mathrm{P}$ concentrations of the overgrowths were

150 calculated from the difference of phosphate added to the solution and that remaining in solution 
151 at the end of the experiment (from measured reactive phosphate concentration and total solution

152 volume), estimating the mass of calcium carbonate precipitated from the amount of Ca added to

153 the growth solution. Powder X-ray diffraction indicates that all synthetic coprecipitates were

154 composed dominantly of aragonite, but that some contain as much as $9 \%$ calcite (Milliman and

155 Bornhold, 1973; Morse et al, 1985).

\subsection{Laser ablation ICPMS analysis}

The $\mathrm{P} / \mathrm{Ca}$ ratios and the $\mathrm{P}$ concentrations were obtained following the analytical method

159 by Montagna et al. (2006, 2007). We used a high sensitivity pulsed laser ablation system,

160 coupled with a Fison PQII ICPMS with enhanced sensitivity. This laser ablation system housed

161 at RSES (Canberra) uses a LambdaPhysik LPX 120i argon fluoride 193nm excimer laser. All the

162 coral samples were scanned at $20 \mu \mathrm{m} / \mathrm{s}$ using a $20 \mu \mathrm{m}$ wide and $220 \mu \mathrm{m}$ long rectangular laser

163 beam mask with the laser pulsing at $5 \mathrm{~Hz}$ and an energy of $50 \mathrm{MJ}$. Before acquisition, surface

164 contamination was removed by pre-ablating the coral surfaces twice, with a $230 \mu \mathrm{m}$ diameter

165 spot followed by the same rectangular slit used for the analysis. A pressed powder coral disc and

166 the NIST glass standard 612, chosen for its P concentration comparable to the coral samples,

167 were analysed before and after each run on the samples, together with the acquisition of the

168 background (gas blank) for 60s, allowing correction for long-term machine drift during analysis.

169 The precision for ${ }^{31} \mathrm{P}$, calculated as the RSD $(1 \sigma /$ mean) of 60 s acquisition on the NIST 612 was $170 \sim 6 \%$.

171 The P concentrations of Desmophyllum dianthus and Flabellum sp were obtained both on

172 the outer faces of the S1 septum and on the thecal wall, whereas Lophelia pertusa was only 
173 analysed along the theca. It was not possible for the Porites coral to discriminate between the

174 theca and the septa and the $\mathrm{P}$ concentration represents an average over these skeletal portions.

\subsection{Bulk solution ICPMS analysis}

Analyses of ${ }^{31} \mathrm{P}$ and ${ }^{43} \mathrm{Ca}$ were determined by inductively coupled plasma mass

178 spectrometry (ICP-MS) using the multi-collector Axiom in single collection mode at Lamont-

179 Doherty Earth Observatory and following the standard addition method (Vandecasteele and Block, 1997) to correct for the matrix effect.

For some of the samples analysed by ${ }^{31} \mathrm{P}$ NMR, a precisely-weighted amount of coral

182 powder was dissolved in double distilled $\mathrm{HNO}_{3}$ and further diluted in $1 \% \mathrm{HNO}_{3}$ for the analysis

183 by ICPMS. Procedural blank solutions were made with the same vials and acid used for the

184 treatment of the samples. The analysis was carried out in two separate sessions: in the first

185 session the concentration of $\mathrm{P}$ was measured in solutions with a final dilution factor of $\sim 2000$.

186 The solutions were further diluted to a dilution factor of $\sim 6000$ and analysed for calcium

187 concentration during a second analytical session.

188 A multi-element stock standard mixture was prepared gravimetrically with $1 \% \mathrm{HNO}_{3}$ and 189 High-Purity Standards (Charleston, $\mathrm{SC} ; 1000 \pm 3 \mu \mathrm{g} \mathrm{mL} \mathrm{L}^{-1}$ in $0.05 \% \mathrm{HNO}_{3} \mathrm{v} / \mathrm{v}$ for P; $1000 \pm 3 \mu \mathrm{g}$

$190 \mathrm{~mL}^{-1}$ in $3 \% \mathrm{HNO}_{3} \mathrm{v} / \mathrm{v}$ for $\mathrm{Mg}$ and $\mathrm{Sr} ; 10 \mu \mathrm{gL}^{-1}$ in $4 \% \mathrm{HNO}_{3}$ for $\mathrm{Ca}$ ), mixed in appropriate

191 concentrations to match the typical composition of coral skeletons. Two four-point standard 192 curves were prepared by adding increasing volumes of the stock solution to six pre-cleaned vials 193 containing a constant volume of the unknown solutions (sample "G15606 S" and "DD Chile S194 ct") and $1 \% \mathrm{HNO}_{3}$. The first point of each standard curve consists of one unspiked original 195 sample. A third three-point standard curve was obtained by adding increasing amounts of a stock 
196 solution containing solely P (High-Purity Standards) to pre-cleaned vials having a constant

197 volume of the unknown solution (sample "G16505 S") and $1 \% \mathrm{HNO}_{3}$. The results of the two

198 standardization methods were compared to verify the quality of the measurements.

199 A drift correction was performed by analysing an indium spiked mixed solution every five

200 samples and using a linear interpolation for all the elements. All the working solutions were also

201 spiked with indium as an internal standard to further correct for the instrumental drift. The

202 standards and unknown solutions were introduced to the plasma by a self-aspirating nebulizer

203 with an uptake rate of $\sim 30 \mu \mathrm{L} \mathrm{min}^{-1}$ in conjunction with a Cetac Aridus desolvating system.

204 Analytical reproducibility based on the RSD ( $1 \sigma$ mean) of ten analyses of the Porites coral

205 standard JCp-1 (Geological Survey of Japan; run as an unknown) are $\sim \pm 9.5 \%$ for P/Ca and P

206 concentration. Procedural blank for P, which was subtracted from the sample raw counts, was

207 typically $<20 \%$.

208

209 2.4. Solid-state NMR spectroscopy

210 The ${ }^{31} \mathrm{P}$ single pulse magic angle spinning (SP/MAS) NMR and ${ }^{31} \mathrm{P}\left\{{ }^{1} \mathrm{H}\right\}$ cross

211 polarization (CP) MAS NMR spectra were collected on a $400 \mathrm{MHz}$ Varian Inova spectrometer at

212 operating frequencies of 161.8 and $399.8 \mathrm{MHz}$ for ${ }^{31} \mathrm{P}$ and ${ }^{1} \mathrm{H}$, respectively. Samples were

213 contained in $7.5 \mathrm{~mm}$ outside diameter (o.d.) $\mathrm{Si}_{3} \mathrm{~N}_{4}$ rotors and spun at $5 \mathrm{kHz}$. The probe and rotor

214 assemblies yielded no detectable ${ }^{31} \mathrm{P}$ NMR signal after several days of acquisition. However,

215 standard $\mathrm{ZrO}_{2}$-based rotor sleeves can give a broad, weak ${ }^{31} \mathrm{P}$ signal in the orthophosphate region

216 (here taken to be the ${ }^{31} \mathrm{P}$ spectral region from -5 to $12 \mathrm{ppm}$; Turner et al, 1986). The ${ }^{1} \mathrm{H}$ SP/MAS

217 NMR and ${ }^{1} \mathrm{H}\left\{{ }^{31} \mathrm{P}\right\}$ rotational echo double resonance (REDOR) spectra were obtained using a

218 Chemagnetics probe assembly configured for $4 \mathrm{~mm}$ (o.d.) rotors and modified to yield very low 
$219{ }^{1} \mathrm{H}$ background signal. The ${ }^{31} \mathrm{P}\left\{{ }^{1} \mathrm{H}\right\}$ Heteronuclear Correlation (HetCor) spectra were obtained 220 using a probe configured for $3.2 \mathrm{~mm}$ (o.d.) rotors and were collected as a total of 100

221 hypercomplex points in $t 1$ with a $10 \mu$ s increment, corresponding to a $100 \mathrm{kHz}$ spectral window

222 in the ${ }^{1} \mathrm{H}$ dimension. A Carr-Purcell-Meiboom-Gill (CPMG) type acquisition was implemented 223 to shorten the time needed to perform the HetCor experiment. The ${ }^{19} \mathrm{~F}\left\{{ }^{31} \mathrm{P}\right\}$ REDOR, ${ }^{31} \mathrm{P}\left\{{ }^{13} \mathrm{C}\right\}$

$224 \mathrm{SP} / \mathrm{REDOR}$, and ${ }^{1} \mathrm{H} \rightarrow{ }^{31} \mathrm{P}\left\{{ }^{13} \mathrm{C}\right\} \mathrm{CP} / \mathrm{REDOR}$ spectra were collected on a $500 \mathrm{MHz}$ Varian 225 Infinity Plus spectrometer at operating frequencies of 125.7, 202.3, 470.2, and 499.8 $\mathrm{MHz}$ for

$226{ }^{13} \mathrm{C},{ }^{31} \mathrm{P},{ }^{19} \mathrm{~F}$ and ${ }^{1} \mathrm{H}$ respectively. The ${ }^{19} \mathrm{~F}\left\{{ }^{31} \mathrm{P}\right\}$ REDOR spectra were collected using a

227 Varian/Chemagnetics T3-type probe configured for $3.2 \mathrm{~mm}$ (o.d.) rotors and to give a very low

$228{ }^{19} \mathrm{~F}$ background. The ${ }^{31} \mathrm{P}\left\{{ }^{13} \mathrm{C}\right\} \mathrm{SP}$ and ${ }^{1} \mathrm{H} \rightarrow{ }^{31} \mathrm{P}\left\{{ }^{13} \mathrm{C}\right\} \mathrm{CP} / \mathrm{REDOR}$ spectra were collected using 229 a Varian HXY probe configured for $4 \mathrm{~mm}$ (o.d) rotors. The ${ }^{31} \mathrm{P}$ MAS NMR spectra are 230 referenced with respect to $85 \%$ phosphoric acid using hydroxylapatite as a secondary reference

231 set to $2.65 \mathrm{ppm}$. The ${ }^{1} \mathrm{H}$ MAS NMR spectra are referenced with respect to tetramethylsilane 232 using hydroxylapatite as a secondary reference set to $0.2 \mathrm{ppm}$. The ${ }^{19} \mathrm{~F}$ spectra were referenced 233 with respect to $\mathrm{CCl}_{3} \mathrm{~F}\left(\mathrm{C}_{6} \mathrm{~F}_{6}=142 \mathrm{ppm}\right)$.

\section{RESULTS AND DISCUSSION}

\section{1. ${ }^{31} \mathrm{P}$ SP/MAS and ${ }^{31} \mathrm{P}\left\{{ }^{1} \mathrm{H}\right\} \mathrm{CP} / \mathrm{MAS}$ NMR}

\subsection{1 ${ }^{31}$ P SP/MAS NMR of Coral Samples}

We obtained solid-state ${ }^{31} \mathrm{P}$ NMR spectra for both aragonitic azooxanthellate and 239 zooxanthellate coral samples having P contents ranging from 16 to $319 \mu \mathrm{g} / \mathrm{g}$ (Fig. 1; Table 1),

240 including septa and thecal wall portions as well as whole coral samples. The ${ }^{31} \mathrm{P}\left\{{ }^{1} \mathrm{H}\right\} \mathrm{CP} / \mathrm{MAS}$ 241 and ${ }^{31} \mathrm{P}$ SP/MAS spectra of a Desmophyllum dianthus septum (DD LM99-124) are presented in 
242 Figure 2 and illustrate the typical spectral profile observed for most samples. These spectra can

243 be described by a sum of two Gaussian peaks centered at ${ }^{31} \mathrm{P}$ chemical shifts $\left(\delta_{\mathrm{P}}\right)$ of 2.7 and 4.0

244 ppm which have full-widths at half maximum (fwhm) of 1.7 and 6.4 ppm, respectively. Both

245 peaks occur in the chemical shift range typical for orthophosphate species (Turner et al., 1986;

246 Kolowith et al., 2001; Cade-Menun, 2005). Given the very low surface area of these samples

247 and that the NMR signal arises from the entire sample volume, the peaks correspond mainly to $\mathrm{P}$

248 contained within the sample interior and cannot be attributed solely to surface adsorbed species.

249 One possibility for the host of the P would be Fe-Mn oxide crust that may not have been

250 removed from the surface abrasion techniques employed. However, any $\mathrm{P}$ occurring in Fe-Mn-

251 oxides would not be observable under our experimental conditions, owing to extreme peak shifts

252 and broadening of the ${ }^{31} \mathrm{P}$ resonance that would result from magnetic interactions with unpaired

253 electrons (Grey et al., 2010). Therefore, we can rule out P associated with Fe-Mn oxides as the

254 source of the observed ${ }^{31} \mathrm{P}$ NMR signal.

255 3.1.2. ${ }^{31} \mathrm{P}\left\{{ }^{1} \mathrm{H}\right\}$ CP/MAS NMR of Coral Samples

256 The two observed peaks exhibit distinct variation in ${ }^{31} \mathrm{P}\left\{{ }^{1} \mathrm{H}\right\} \mathrm{CP} / \mathrm{MAS}$ intensity with

257 contact time (CP kinetics), which allows them to be separated easily depending on the

258 acquisition conditions (Fig. 2). The CP kinetics in the simplest cases can be described by a sum

259 of two exponential functions, in which intensity increases at short contact times with a time

260 constant $\mathrm{T}_{\mathrm{PH}}$ and then decreases at longer times with a time constant $\mathrm{T}_{1 \rho, \mathrm{H}}$ (Kolodziejski and

261 Klinowski, 2002). $\mathrm{T}_{\mathrm{PH}}$ relates to the spatial proximity of $\mathrm{P}$ to $\mathrm{H}$, and $\mathrm{T}_{1 \rho, \mathrm{H}}$ to the relaxation of the

$262{ }^{1} \mathrm{H}$ nuclei, usually reflecting dynamical processes. The peak at $\delta_{\mathrm{P}}=2.7 \mathrm{ppm}(\mathrm{Fig}$. 2a) is

263 dominant at long contact times due to a relaxation time of associated ${ }^{1} \mathrm{H}\left(\mathrm{T}_{1 \rho, \mathrm{H}}>10 \mathrm{~ms}\right)$ that is

264 long compared to that for the peak at $\delta_{\mathrm{P}}=4.0 \mathrm{ppm}\left(\mathrm{T}_{1 \rho, \mathrm{H}}=1 \mathrm{~ms}\right)$. We assign this peak at $\delta_{\mathrm{P}}=$ 
$2.7 \mathrm{ppm}$ to crystalline apatite, because its spectral characteristics closely match those reported

266 previously for this phase, including its chemical shift, narrow width (characteristic of a highly

267 ordered crystalline phase), and long ${ }^{1} \mathrm{H} \rightarrow{ }^{31} \mathrm{P} \mathrm{CP}$ time $\left(\mathrm{T}_{\mathrm{PH}}=5 \mathrm{~ms}\right)$ and $\mathrm{T}_{1 \rho, \mathrm{H}}$ (Rothwell et al.,

268 1980; Belton et al., 1988; Kaflak et al., 2006). The broad peak at $\delta_{\mathrm{P}}=4.0 \mathrm{ppm}$ dominates at

269 short contact times (Fig. 2c) because of its much shorter ${ }^{1} \mathrm{H} \rightarrow{ }^{31} \mathrm{P} \mathrm{CP}$ time $\left(\mathrm{T}_{\mathrm{PH}}=0.4 \mathrm{~ms}\right)$. This

270 short $\mathrm{T}_{\mathrm{PH}}$ value indicates that the $\mathrm{P}$ represented by the $\delta_{\mathrm{P}}=4.0 \mathrm{ppm}$ peak are in close spatial

271 proximity to rigid structural $\mathrm{H}$ (separations less than $4 \AA$ ). The two peaks fit to the CP/MAS

272 spectra also describe the quantitative SP spectra, indicating that they represent the $\mathrm{P}$ distribution

273 in the sample. With few exceptions, the spectra of the other deep-water corals are similar,

274 differing only in the total signal intensity observed and relative proportion of that signal which is

275 attributed to apatite. The chemically cleaned subsamples of Desmophyllum dianthus produce

276 spectra which can be fit with peaks having the same chemical shifts and widths as those observed

277 for the untreated samples. This result indicates that the $\mathrm{P}$ distribution in the cleaned samples is

278 essentially similar to that in the same samples which had only undergone surface abrasion

279 although the signal intensity is much reduced (Fig. 3).

280 3.1.3. Identification of additional minor P-species

281 Two other samples examined contain P environments not found in most of the other

282 deep-water coral specimens. Spectra of a Madrepora oculata sample (MO CORAL2 75) contain

283 a narrow peak at $\delta_{\mathrm{P}}=-0.6 \mathrm{ppm}(1.1 \mathrm{ppm}$ fwhm $)$, in addition to the broad peak near $\delta_{\mathrm{P}}=4 \mathrm{ppm}$

284 common to all of the coral aragonite examined (Fig. 1g). The small width of the peak at -0.6

285 ppm suggests that it could arise from a crystalline inorganic phosphate phase (Rothwell et al.,

286 1980; Belton et al., 1988; Mason et al., 2007), but the chemical shift is also consistent with

287 phosphate esters (Cade-Menun, 2005) although such organic-P usually produces broader peaks 
288 in solid-state ${ }^{31} \mathrm{P}$ NMR spectra. The origin of this peak was not investigated further, but its

289 presence illustrates that other P-containing materials could be present in coralline aragonite. The

290 Porites sp. (PO FR2004) sample we examined yields spectra containing a distinct peak at $\delta_{\mathrm{P}}=$

$29122.5 \mathrm{ppm}(3.0 \mathrm{ppm}$ fwhm), in addition to the broad peak near 4 ppm (Fig. 1h). This $22.5 \mathrm{ppm}$

292 chemical shift falls outside the range for phosphate, but is diagnostic of phosphonate (Glonek et

293 al., 1970; Kolowith et al., 2001, Cade-Menun, 2005), which contains C-P bonds and indicates the

294 presence of organic P in the sample. The Madrepora and Porites samples were not physically

295 cleaned, representing the whole coral skeleton and the sampled areas may include remnant

296 cellular material from either the coral polyp, products of bioerosion or endosymbionts (the latter

297 refers only to Porites), although phosphonates are known to adsorb strongly to calcite surfaces

298 (Sawada et al., 2003; Kan et al., 2005) and could interact similarly with aragonite and become

299 occluded during crystal growth. Since the NMR methods applied here cannot differentiate

300 between organic matter occluded in the aragonite, and that of remnant cellular material, we did

301 not explore these samples further.

302 3.1.4. ${ }^{31}$ P NMR of Synthetic Aragonite/phosphate coprecipitates

303 A broad peak near $\delta_{\mathrm{P}}=4 \mathrm{ppm}$ that is similar in both chemical shift, width, and CP

304 kinetics behavior to the broad peak observed for the coral samples dominates ${ }^{31} \mathrm{P}$ NMR spectra

305 of synthetic aragonite precipitated from solutions containing 1 - $3 \mu \mathrm{M}$ DIP (Fig. 1 i-j). The

306 synthetic samples range in P concentration from 100 to $700 \mu \mathrm{g} / \mathrm{g}$ but their NMR spectra showed

307 no significant differences other than corresponding variations in signal intensity. The ${ }^{31} \mathrm{P}$

308 CP/MAS spectra of these aragonite/phosphate coprecipitates also contain small, narrow peaks at

$309 \delta_{\mathrm{P}}=11.4$ and $8.4 \mathrm{ppm}$ that are not apparent in the quantitative ${ }^{31} \mathrm{P}$ SP/MAS spectra (Fig. $\left.1 \mathrm{i}, \mathrm{j}\right)$, 
310 suggesting they arise from phosphate associated with $\mathrm{H}$ in minor unidentified crystalline phases.

311 A peak for apatite-like orthophosphate was not observed for any synthetic sample.

312 3.2. ${ }^{31} \mathbf{P}\left\{{ }^{1} \mathbf{H}\right\}$ HetCor NMR of Coral samples

313 Since the source of $\mathrm{P}$ in the synthetic samples is known we can assign the resulting NMR

314 signal at $\delta_{\mathrm{P}}=4 \mathrm{ppm}$ to inorganic phosphate. However, the source of the $\delta_{\mathrm{P}}=4 \mathrm{ppm}$ peak in the

315 coral samples cannot be inferred simply by comparison of the ${ }^{31} \mathrm{P}$ data because organic

316 phosphate esters can give NMR peaks in the same ${ }^{31} \mathrm{P}$ chemical shift region (Teleman et al.,

317 1999; Paytan et al., 2003; Cade-Menun, 2005). Distinction between organic and inorganic

318 phosphate can be aided by ${ }^{1} \mathrm{H}$ NMR of the $\mathrm{H}$ associated with $\mathrm{P}$, since the ${ }^{1} \mathrm{H}$ chemical shifts of

319 organophosphate aliphatic $\mathrm{H}$, which range from $\delta_{\mathrm{H}}=2.0$ to 4.0 (Teleman et al., 1999), differ

320 from those typical of $\mathrm{HPO}_{4}$ groups and structural $\mathrm{H}_{2} \mathrm{O}$, in the 4.0 to $12.0 \mathrm{ppm}$ range (Yesinowski

321 and Eckert, 1987). We used ${ }^{31} \mathrm{P}\left\{{ }^{1} \mathrm{H}\right\}$ HetCor methods to selectively observe the ${ }^{1} \mathrm{H}$ spectra of

322 only those $\mathrm{H}$ located near $\mathrm{P}$, by detecting the ${ }^{1} \mathrm{H}$ from which magnetization is transferred during

$323 \quad{ }^{1} \mathrm{H} \rightarrow{ }^{31} \mathrm{P} \mathrm{CP}$. The ${ }^{31} \mathrm{P}$-detected ${ }^{1} \mathrm{H}$ spectrum for a sample containing no apatite (DD G16505 S)

324 shows a narrow peak at $\delta_{\mathrm{H}}=5.5 \mathrm{ppm}$ that is underlain by a broad peak centered near $7.5 \mathrm{ppm}$

325 (8.2 ppm fwhm) with a broad spinning sideband pattern (Fig. 4a). Neither peak occurs in the

326 chemical shift range for aliphatic $\mathrm{H}$ in organophosphates (Teleman et al., 1999), but are

327 consistent with assignment to molecular water undergoing restricted motion (5.5 ppm) and either

328 rigid structural water or weakly H-bonded hydrogen phosphate (7.5 ppm). The synthetic

329 aragonite/phosphate coprecipitate yielded a ${ }^{31} \mathrm{P}$-detected ${ }^{1} \mathrm{H}$ spectrum (Fig. $4 \mathrm{~b}$ ) that is similar to

330 that of the coral aragonite, containing a narrow peak at $\delta_{\mathrm{H}}=6 \mathrm{ppm}$ and a broader peak centered

331 near 8 ppm with a substantial spinning sideband pattern. Acquisition of these HetCor spectra

332 required over one week of spectrometer time each, making it impractical to collect such data for 
333 all of the coral samples. Considering that the broad peak near $+4 \mathrm{ppm}$ (the main signal in ${ }^{31} \mathrm{P}$

334 NMR spectra of the coral and synthetic samples) exhibits the same CP kinetics behavior in all

335 samples and that the $\mathrm{CP}$ kinetics depends on the nature of $\mathrm{H}$ near $\mathrm{P}$, it is reasonable to infer that

336 the hydrogen environments observed in these HetCor spectra represent those associated with $\mathrm{P}$ in

337 all samples which yield a similar ${ }^{31} \mathrm{P}$ NMR signal .

338 3.3. REDOR NMR

339 3.3.1. ${ }^{31} P\left\{{ }^{13} C\right\}$ REDOR NMR of synthetic aragonite/phosphate coprecipitates

340 The similarity of both the ${ }^{31} \mathrm{P}$ and $\left({ }^{31} \mathrm{P}\right.$-detected) ${ }^{1} \mathrm{H}$ NMR data for the coral aragonite to

341 those for the synthetic aragonite/phosphate coprecipitate provides strong evidence that the nature

342 of the phosphate is the same in both, i.e. orthophosphate. Based only on these NMR data,

343 however, occurrence of phosphate as a substitution defect in the aragonite structure cannot be

344 distinguished from a separate amorphous Ca-phosphate phase, since the latter yield similar

345 spectra (Rothwell et al., 1980; Kaflak et al., 2006). A test for the presence of phosphate as

346 defects in the aragonite structure can be obtained from a ${ }^{31} \mathrm{P}\left\{{ }^{13} \mathrm{C}\right\}$ REDOR NMR experiment,

347 which depends on atomic-scale spatial proximity between ${ }^{31} \mathrm{P}$ and ${ }^{13} \mathrm{C}$ nuclei (within a few $\AA$ ).

348 For this experiment we used an aragonite/phosphate coprecipitate synthesized with ${ }^{13} \mathrm{C}$-enriched

349 carbonate because REDOR detects proximity to only the NMR-active ${ }^{13} \mathrm{C}$ isotope, the natural

350 abundance of which $(1.1 \%)$ is too low to yield a detectable REDOR effect for the very weak ${ }^{31} \mathrm{P}$

351 signal. The REDOR experiment compares two ${ }^{31} \mathrm{P}$ spectra, a control spectrum $\left(S_{0}\right.$; Fig. 5a,c),

352 containing signal from all $\mathrm{P}$ in the sample, and a REDOR spectrum $(S$; Fig. 5b,d) obtained in a

353 similar manner as for $S_{0}$, except that dephasing pulses are applied at the ${ }^{13} \mathrm{C}$ frequency to re-

354 introduce ${ }^{31} \mathrm{P} /{ }^{13} \mathrm{C}$ dipolar coupling, causing a decrease in signal intensity for $\mathrm{P}$ located near ${ }^{13} \mathrm{C}$. 
355 Simulations of the REDOR experiment indicate that no significant decrease in the ${ }^{31} \mathrm{P}$ peak 356 intensity should occur for P located farther than $5 \AA$ from ${ }^{13} \mathrm{C}$.

357 The REDOR results at a $6.7 \mathrm{~ms}$ dephasing period show a large REDOR fraction

$358\left[\left(S_{0}-S\right) / S_{0}\right]=0.7$ for the broad peak near $\delta_{\mathrm{P}}=4 \mathrm{ppm}$. This value is similar to but somewhat lower

359 than the maximum REDOR fraction (0.90) that could be expected for phosphate in the aragonite

360 structure, estimated using the SPINEVOLUTION software (Veshort and Griffen, 2006) with a

$361 \mathrm{P} / \mathrm{C}$ configuration corresponding to substitution of phosphate for a carbonate group in the

362 aragonite structure (6 C surrounding a central P at a distance of $3.2 \AA$; Fig. 6). A REDOR

363 fraction smaller than this maximum value would be expected to result from structural disruption

364 around a phosphate defect that would lead to fewer adjacent carbonate groups and/or longer P-C

365 distances. However, multiple short $(<4 \AA) \mathrm{P}-\mathrm{C}$ distances are required to explain this $\mathrm{P} / \mathrm{C}$

366 REDOR result, which would seem possible only if the phosphate occurs in the structure of the

367 carbonate phase. Similar REDOR results were obtained whether SP or CP excitation of ${ }^{31} \mathrm{P}$ was

368 used (cf. Fig. 5a,b and c,d), strongly suggesting that much of the phosphate in aragonite is

369 associated with $\mathrm{H}$, and hence that $\mathrm{H}$-bearing species play a role in accommodating the defect.

370 3.3.2. ${ }^{1} H\left({ }^{31} P\right\}$ and ${ }^{19} F\left\{{ }^{1} H\right\}$ REDOR NMR of coral samples

371 To determine the nature of the crystalline apatite inclusions that occur in some coral

372 specimens, ${ }^{1} \mathrm{H}\left\{{ }^{31} \mathrm{P}\right\}$ and ${ }^{19} \mathrm{~F}\left\{{ }^{31} \mathrm{P}\right\}$ REDOR NMR experiments were applied that would identify

373 signals from $\mathrm{H}$ or $\mathrm{F}$ located in close proximity to $\mathrm{P}$. Fluorapatite is a significant sink for

374 phosphate in marine sediments (Kim et al., 1999) whereas biogenic apatite is composed

375 primarily of carbonate-substituted hydroxylapatite (Elliot, 2002). The ${ }^{19} \mathrm{~F}$ NMR spectrum for the

376 Flabellum sp. theca sample (Fig. 7) is complex with multiple peaks. None of these peaks can be

377 assigned to fluorapatite, which would occur at a chemical shift near -102 ppm (Braun and Jana, 
378 1995), nor to any other phase for which ${ }^{19} \mathrm{~F}$ NMR data have been reported in the literature. In 379 addition, no ${ }^{19} \mathrm{~F}\left\{{ }^{31} \mathrm{P}\right\}$ REDOR effect was observed for any ${ }^{19} \mathrm{~F}$ peak, further indicating that no

380 significant fraction of the $\mathrm{F}$ is associated with $\mathrm{P}$, and hence that the apatite detected by ${ }^{31} \mathrm{P}$ NMR 381 does not correspond to fluorapatite (Fig. 7). The ${ }^{1} \mathrm{H}\left\{{ }^{31} \mathrm{P}\right\}$ REDOR data (Fig. 8) were obtained 382 for a Desmophyllum dianthus theca wall sample (DD CHILE Coral A). The control spectrum 383 contains peaks at $\delta_{\mathrm{H}}=4.8$ and $1.5 \mathrm{ppm}$ that do not exhibit decreased intensity in the REDOR 384 spectrum, but which correspond well to signals assigned to water molecules and structural 385 hydroxyl in a previous NMR study of calcium carbonate minerals (Gaffey, 1995). A very small 386 peak occurs near $\delta_{\mathrm{H}}=0.2 \mathrm{ppm}$ that is near the chemical shift reported for hydroxylapatite 387 (Yesinowski and Ekert, 1987), but which is marginally above the noise. This peak is clearly 388 absent from the ${ }^{1} \mathrm{H}\left\{{ }^{31} \mathrm{P}\right\}$ REDOR spectrum (cf. Fig. 8a and b), indicating proximity to $\mathrm{P}$ and 389 consistent with assignment to hydroxylapatite. These observations support the idea that the 390 narrow peak in ${ }^{31} \mathrm{P}\left\{{ }^{1} \mathrm{H}\right\} \mathrm{CP}$ spectra (Fig. 2a) arises from hydroxylapatite inclusions.

391 Hydroxylapatite can also contain significant amounts of F; however, the hydroxyl peak in a 392 mixed $\mathrm{OH}, \mathrm{F}$ apatite would be expected to occur at a more positive chemical shift of about 1.2 to $393 \quad 1.4$ ppm (Yesinowski and Ekert, 1987).

\section{3.4. Quantification of the ${ }^{31}$ P NMR signal}

395 3.4.1. Relative hydroxylapatite content

396 Since acquisition of quantitative ${ }^{31} \mathrm{P}$ NMR spectra is extremely time-consuming, and impractical 397 at $\mathrm{P}$ contents less than about $200 \mu \mathrm{g} / \mathrm{g}$, we developed a relationship between relative intensities 398 in ${ }^{31} \mathrm{P}$ SP/MAS and ${ }^{31} \mathrm{P}\left\{{ }^{1} \mathrm{H}\right\} \mathrm{CP} / \mathrm{MAS}$ spectra as a means to estimate the proportion of 399 hydroxylapatite. Ideally the relative abundances of $\mathrm{P}$ corresponding to the peaks at $\delta_{\mathrm{P}}=2.7$ and 4 400 ppm would be derived through the careful integration of ${ }^{31} \mathrm{P}$ SP/MAS NMR spectra. However, 
401 the low concentration of $\mathrm{P}$ in the samples and the long experimental relaxation delays (100's of

402 seconds) needed for quantitative results required almost 4 days of continuous spectrometer time 403 for some samples. Acquisition of a ${ }^{31} \mathrm{P}\left\{{ }^{1} \mathrm{H}\right\} \mathrm{CP} / \mathrm{MAS}$ NMR spectrum takes less than half the

404 time to obtain similar signal to noise ratio but the results are not quantitative without careful 405 analysis of CP kinetics (Kolodziejski and Klinowski, 2002), which can be time-consuming.

406 Therefore we estimated the relative abundance of apatite in the aragonitic coral skeletons from

407 CP/MAS spectra using a correlation between SP/MAS and CP/MAS intensities similar to that

408 described by Mason et al. (2007). The integrated intensity ratio of the peaks at 4 and $2.7 \mathrm{ppm}$

409 was determined from a SP spectrum acquired under quantitative conditions for a sample that

410 contained a high fraction of P in apatite (Desmophyllum dianthus septa sample: DD LM99 124).

411 These integrated intensities are proportional to the number of $\mathrm{P}$ in the respective environments, 412 meaning that $35 \pm 5 \%$ of the $\mathrm{P}$ in this sample occurs in apatite (peak at $2.7 \mathrm{ppm}$; Table 1). A

413 correction factor for CP/MAS spectra was then obtained by comparing this SP integrated

414 intensity ratio with that obtained from a CP/MAS spectrum of the same sample (1 ms contact

415 time). This correction factor was applied to the integrated intensity ratios obtained from

$416 \mathrm{CP} / \mathrm{MAS}$ spectra of the other samples (1 ms contact time), yielding estimates for the percentage

417 of the ${ }^{31}$ P-NMR detected $\mathrm{P}$ that occurs in apatite (Table 1, last column).

418 3.4.2. P concentrations in the solid

419 For several samples we independently measured P content using solution ICPMS in

420 addition to the LA-ICPMS analyses (Table 2). The solution ICPMS data provides an accurate

421 measure of the bulk P content of these samples and any disparity with the LA-ICPMS data was

422 attributed to the former method, which only analyzes the outer septal layers that may not

423 accurately reflect the bulk P content which is detected by NMR (Montagna et al., 2009; 
424 Anagnostou et al., 2011). We also estimated the bulk P content for several samples from NMR

425 data for comparison to the solution ICPMS results. The ${ }^{31} \mathrm{P}\left\{{ }^{1} \mathrm{H}\right\} \mathrm{CP} / \mathrm{MAS}$ NMR intensity of a

426 sample of known bulk P content (synthetic aragonite containing $530 \mu \mathrm{g} / \mathrm{g} \mathrm{P}$ as determined from

427 the synthesis method) was compared to that for the unknown, collected under identical

428 acquisition conditions ( $5 \mathrm{kHz}$ spinning rate, $2 \mathrm{~ms}$ contact time, $2.0 \mathrm{~s}$ pulse delay) and scaled by

429 mass and number of acquisitions. The synthetic aragonite yielded no detectable signal for apatite

430 in CP/MAS spectra collected under conditions (10 ms contact time) that would favor its

431 observation. We assume that the CP kinetics for the phosphate species are reasonably consistent

432 among samples. Using this method we estimate $77 \pm 12 \mu \mathrm{g} / \mathrm{g}$ P for the DD-CHILE-TW, 200

$433 \pm 28 \mu \mathrm{g} / \mathrm{g}$ P for the LP COBAS 109, and $126 \pm 18 \mu \mathrm{g} / \mathrm{g}$ P for the DD-CHILE-S samples. The

434 concentrations for the two former samples agree well with the solution ICPMS analyses (Table

435 2). A portion of the sample DD-CHILE-TW that was chemically treated using the method

436 designed to remove surface sorbed metals and metal oxides (DD-CHILE-TW-ct) showed a 54\%

437 reduction of $\mathrm{P}$ content to $35 \pm 5 \mu \mathrm{g} / \mathrm{g}$ P. However, its ${ }^{31} \mathrm{P} \mathrm{CP} / \mathrm{MAS}$ NMR spectral profile did not

438 differ significantly from that of the untreated material (cf. Fig 3). These results suggest that both

439 the CP/MAS NMR spectra and the solution ICPMS methods are detecting the same pool of P,

440 and that there is no significant fraction of $\mathrm{P}$ undetected by NMR. Furthermore, although the

441 chemical cleaning procedure appears to preferentially remove aragonite around phosphate

442 defects, there does not appear to be a significant difference in the bonding environment of the

443 remaining phosphate.

\section{$444 \quad$ 3.4.3. Absolute hydroxylapatite content}

445 Combining the relative abundance of hydroxylapatite derived from NMR with absolute

446 P-contents from solution ICPMS data on the same sample, the amount of hydroxylapatite can be 
447 estimated (Table 2). The result is a wide range of hydroxylapatite contents with no obvious

448 relationship to environmental factors such as depth and DIP. Nor do the concentrations of

449 hydroxylapatite correlate with the absolute P content determined from solution ICPMS. For

450 example, solution ICPMS data indicate DD G16505 TW contains only $22 \mu \mathrm{g} / \mathrm{g}$ P, but a large

451 percentage, $31 \%$, occurs in hydroxylapatite. Moreover, there seems to be no clear correlation

452 between the apatite content and the preservation state of the corals (i.e. alive or fossil).

\section{3.5. Nature of $P$ in coral aragonite}

454 Previous studies have suggested that the majority of $\mathrm{P}$ present in coral skeletons exists as 455 organic P-species (Dodge et al., 1984; Shotyk et al., 1995; LaVigne et al., 2008; Anagnostou et

456 al, 2011). This conclusion is based primarily on the results of various extraction procedures

457 relying on assumptions about the solubility and availability of organic versus inorganic P-

458 species. Since many studies assume that the acid-insoluble fraction contains only organic $\mathrm{P}$, the

459 presence of relatively insoluble Ca-phosphates and possibly adsorption of phosphate onto

460 insoluble particles upon release by aragonite dissolution could skew the results of such an assay.

461 The results of the present study clearly show that the principal P-species present in most coral

462 aragonite samples closely resembles spectroscopically that produced by simply incorporating

463 dissolved inorganic phosphate during aragonite crystal growth.

464 The chemical cleaning methods employed here were originally designed to remove oxide

465 coatings and metals not incorporated into the aragonite structure. We do observe a substantial

466 decrease in the P concentration of the chemically treated samples. However, we attribute this

467 result to preferential dissolution of phosphate-rich regions, rather than the removal of $\mathrm{P}$

468 associated with Fe-Mn or other metal oxide minerals. The NMR-derived P concentrations for

469 untreated samples are in reasonable agreement with those obtained by solution ICPMS methods 
470 for the same samples. If a significant pool of $\mathrm{P}$ was associated with Fe-Mn crusts a large

471 discrepancy between these values would be expected due to the inability of the NMR methods

472 employed here to observe $\mathrm{P}$ associated with ions having unpaired electrons (Grey et al, 2010).

473 Montagna et al. (2009) and Anagnostou et al. (2011) have shown that the outer surface of

474 coral septa produce higher LA-ICPMS derived P concentrations than the interior portions.

475 Montagna et al. (2009) attributed these differences to the presence of P rich species such as 476 hydroxylapatite in the outer septal surface. Since the NMR methods applied here are bulk

477 techniques, we cannot differentiate between $\mathrm{P}$ contained in P rich outer layers and that contained

478 within the less P rich internal microstructures. Given the results of Montagna et al. (2009), the

479 observed drop in the NMR derived P concentrations after the application of the chemical

480 cleaning methods could be attributed to the removal of defect and P rich portions of the coral

481 aragonite which are more susceptible to dissolution.

\section{3.6. Implications for further studies of $P$ proxies in coral}

483 A robust relationship between $\mathrm{P} / \mathrm{Ca}$ ratio of coral aragonite and DIP suitable for use as a

484 paleo-nutrient proxy would seem possible only if $\mathrm{P}$ occurs in the aragonite structure as phosphate 485 defects. Simple trace element partitioning models developed for inorganic carbonates have been 486 applied to surface and deep-water coral aragonite (Gaetani and Cohen, 2006; Sinclair and Risk, 487 2006; Gagnon et al., 2007), with the assumption that the coral polyp precipitates aragonite 488 extracellularly from a calcifying fluid located between the polyp and the previous skeletal 489 aragonite (Cohen and McConnaughey, 2003). This fluid consists of seawater, which is 490 supersaturated respect to calcium carbonate through an enzymatic input of $\mathrm{Ca}^{2+}$ and removal of $4912 \mathrm{H}^{+}$(Cohen and McConnaughey, 2003). At least three processes could lead to $\mathrm{P}$ incorporation 492 into coral aragonite, including encapsulation of surface precipitates, occlusion of organic matter, 
493 and co-precipitation of dissolved inorganic phosphate as a substitution defect in the aragonite

494 likely initiated as a surface-adsorption complex. Of these, only in the latter could it be expected

495 that equilibrium is established between surface adsorbed phosphate and dissolved phosphate in

496 the aqueous phase as required for a linear partition coefficient (Rimstidt et al., 1998; Curti,

497 1999). Standard methodology used for proxy development such as LA-ICPMS, ion microprobe

498 and and x-ray adsorption spectroscopy (XAS) cannot yet provide the molecular-scale spatial

499 relationships between $\mathrm{P}$ and carbonate necessary to test whether P occurs in the aragonite

500 structure. The results obtained in the present study suggest that co-precipitation of phosphate is

501 the dominant process of $\mathrm{P}$ incorporation in deep-water corals lending support for the use of $\mathrm{P} / \mathrm{Ca}$

502 as a proxy. However, many of the studied samples also contain significant amounts of apatite

503 that could cause systematic error in proxy relationships, but which is easily detected using the

504 methods described here. Given the limited number of samples studied here, and the results

505 showing the incorporation of organo-P-species in some samples, screening of additional coral

506 samples may also be warranted. Taking into account possible contamination by crystalline

507 inclusions, careful selection of the coral portion to be analyzed (e.g. Montagna et al., 2009;

508 Anognastou et al., in press) should make it possible to obtain a more robust P/Ca vs. DIP

509 calibration, useful for paleo-nutrient reconstructions.

510

511 Acknowledgments:

512 This research was supported by the U.S. NSF (EAR-0819838), and instrumentation provided by

513 NSF CHE-03-21001. P. Montagna acknowledges financial support from the Marie Curie

514 International Outgoing Fellowship. Coral collection was funded by CNR grants, ESF

515 Moundforce and EU Hermes projects; Bruno Briano (Savona, Italy) and Günter Försterra kindly 
516 supplied corals from offshore Madagascar and the Chilean fiords, respectively. Ship time of RV

517 Urania provided by CNR is gratefully acknowledged. This is ISMAR-Bologna scientific

518 contribution n. 1688. H.M. was supported through a U.S. Dept. of Education sponsored GAANN

519 fellowship (P200A060248).

520 This work performed under the auspices of the U.S. Department of Energy by Lawrence Livermore

521 National Laboratory under Contract DE-AC52-07NA27344. 


\section{References}

523

524

525

526

527

528

529

530

531

532

533

534

535

536

537

538

539

540

541

542

543

544

545

546

547

548

549

550

551

552

553

554

555

556

557

558

559

560

561

562

563

564

565

566

Ahlgren J., Brabandere H. D., Reitzel K., Rydin E., Gogoll A., and Waldeback M. (2007) Sediment phosphorus extractants for phosphorus-31 nuclear magnetic resonance analyses: A quantitative evaluation. J. Environ. Qual. 36, 892-898

Anagnostou E., Sherrell R. M., Adkins J. F., and Gagnon A. C. (2007) Phosphorus, barium and boron in the deep-sea coral Desmophyllum dianthus: Preliminary calibrations. Geochim. Cosmochim. Acta 71, A22.

Anagnostou E., Sherrell R. M., Gagnon A., LaVigne M., Field M.P., McDonough W.F. (2011) Seawater nutrient and carbonate ion concentrations recorded as $\mathrm{P} / \mathrm{Ca}, \mathrm{Ba} / \mathrm{Ca}$, and $\mathrm{U} / \mathrm{Ca}$ in the deep-sea coral Desmophyllum dianthus. Geochim. Cosmochim. Acta 75, 2529-2543

Belton P. S., Harris R. K., and Wilkes P. J. (1988) Solid-state ${ }^{31}$ P NMR studies of synthetic inorganic calcium phosphates. J. Phys. Chem. Solids 49, 21-27.

Braun M. and Jana C. (1995) ${ }^{19}$ F NMR spectroscopy of fluoridated apatites. Chem. Phys. Lett. 245,19-22.

Broecker, W. S. (1982), Ocean geochemistry during glacial time, Geochim. Cosmochim. Acta, 46, 1689- 1705 .

Cade-Menun B. J. (2005) Characterizing phosphorus in environmental and agricultural samples by ${ }^{31} \mathrm{P}$ nuclear magnetic resonance spectroscopy. Talanta 66, 359-371.

Cheng H., Adkins J., R. Edwards R.L., and Boyle E.A. (2000) U-Th dating of deep sea corals Geochim. Cosmochim. Acta 64, 2401-2416.

Cohen A. L. and McConnaughey T. A. (2003) Geochemical perspectives on coral mineralization. Rev. Min. Geochem. 54, 151-187.

Curti E. (1999) Coprecipitation of radionuclides with calcite: estimation of partition coefficients based on a review of laboratory investigations and geochemical data. Appl. Geochem. 14, 433-445.

Dodge R. E., Jickells T. D., Knap A. H., Boyd S., and Bak R. P. M. (1984) Reef-building coral skeletons as chemical pollution (phosphorus) indicators. Mar. Pollut. Bull. 15, 178-187.

Elliott J. C. (2002) Calcium phosphate biominerals. Rev. Mineral. Geochem. 48, 427-453.

Gaetani G. A., and Cohen A. L. (2006) Element partitioning during precipitation of aragonite from seawater: A framework for understanding paleoproxies. Geochim. Cosmochim. Acta 70, 4617-4634.

Gaffey S. J. (1995) $\mathrm{H}_{2} \mathrm{O}$ and $\mathrm{OH}$ in echinoid calcite: A spectroscopic study. Am. Mineral. 80, 
947-959.

Gagnon A. C., Adkins J. F., Fernandez D. P., and Robinson L. F. (2007) $\mathrm{Sr} / \mathrm{Ca}$ and $\mathrm{Mg} / \mathrm{Ca}$ vital effects correlated with skeletal architecture in a scleractinian deep-sea coral and the role of Rayleigh fractionation. Earth Planet. Sci. Lett. 261, 280-295.

Glonek T., Henderson T. O., Hilderbrand R. L., and Myers T. C. (1970) Biological phosphonates: determination by phosphorus-31 nuclear magnetic resonance. Science 169, 192-194.

Grey, C. P.; Kim, J.; Middlemiss, D. S.; Chernova, N. A.; Zhu, B. Y. X.; Masquelier, C., Linking local environments and hyperfine shifts: a combined experimental and theoretical ${ }^{31} \mathrm{P}$ and ${ }^{7} \mathrm{Li}$ solid-state NMR study of paramagnetic Fe(III) phosphates. J. Am. Chem. Soc. 2010, $132,16825-16840$.

Hinedi Z. R., Goldberg S., Chang A. C., and Yesinowski J. P. (1992) A ${ }^{31}$ P and ${ }^{1}$ H MAS NMR study of phosphate sorption onto calcium carbonate. J. Colloid Interf. Sci. 152, 141-160.

House W. A. and Donaldson L. (1986) Adsorption and coprecipitation of phosphate on calcite. J. Colloid Interf. Sci. 112, 309-324.

LaVigne M., Field, M. P., Anagnostou, E., Grottoli, A. G., Wellington, G. M., and Sherrell, R. M. (2008) Skeletal P/Ca tracks upwelling in Gulf of Panama coral: Evidence for a new seawater phosphate proxy. Geophys. Res. Lett. 35, L05604.

LaVigne M., Matthews K.A., Grottoli A.G., Cobb K.M, Anagnostou E., Cabioch G., and Sherrell R.M. (2010) Coral skeleton P/Ca proxy for seawater phosphate: Multi-colony calibration with a contemporaneous seawater phosphate record. Geochim. Cosmochim. Acta 74, 1282-1293.

Kaflak A., Chmielewski D., Gorecki A., Slorarczyk A., and Kolodziejski W. (2006) Efficiency of ${ }^{1} \mathrm{H} \rightarrow{ }^{31} \mathrm{P}$ cross-polarization in bone apatite and its mineral standards. Solid State NMR 29, 345-348.

Kan A. T., Fu G. M., and Tomson M. B. (2005) Adsorption and precipitation of an aminoalkylphosphonate onto calcite. J. Colloid Interf. Sci. 281, 275-284.

Kim D., Schuffert J. D., and Kastner M. (1999) Francolite authigenesis in California continental slope sediments and its implications for the marine P cycle. Geochim. Cosmochim. Acta 63, 3477-3485.

Kolodziejski W. and Klinowski J. (2002) Kinetics of cross-polarization in solid-state NMR: A guide for chemists. Chem. Rev. 102, 613-628.

Kolowith L. C., Ingall E. D., and Benner R. (2001) Composition and cycling of marine organic phosphorus. Limnol. Oceanogr. 46, 309-320. 
613

614

615

616

617

618

619

620

621

622

623

624

625

626

627

628

629

630

631

632

633

634

635

636

637

638

639

640

641

642

643

644

645

646

647

648

649

650

651

652

653

654

655

656

657

658

Koutsoukos P. G. and Nancollas G. H. (1981) Crystal growth of calcium phosphates: epitaxial considerations. J. Cryst. Growth 53, 10-19.

Kumarsingh K., Laydoo R., Chen J. K., and Siung-Chang A. M. (1998) Historic records of phosphorus levels in the reef-building coral Montastrea annularis from Tobago, West Indies. Mar. Pollut. Bull. 36, 1012-1018.

Mason H. E., Frisia S., Tang Y., Reeder R. J., and Phillips B. L. (2007) Phosphorus speciation in calcite speleothems determined from solid-state NMR spectroscopy. Earth Planet. Sci. Lett. 254, 313-322.

Millero F., Huang F., Zhu X. R., Liu X. W., and Zhang J. Z. (2001) Adsorption and desorption of phosphate on calcite and aragonite in seawater. Aquat. Geochem. 7, 33-56.

Milliman J. D. and Bornhold B. D., (1973) Peak height versus intensity analysis of X-ray diffraction data. Sedimentology 20, 445-448

Montagna P., McCulloch M., Taviani M., Mazzoli C., and Vendrell B. (2006) Phosphorus in cold-water corals as a proxy for seawater nutrient chemistry. Science 312, 1788-1791.

Montagna P., McCulloch M., Mazzoli C., Silenzi S. and Odorico R. (2007). The non-tropical coral Cladocora caespitosa as the new climate archive for the Mediterranean Sea: highresolution ( $\sim$ weekly) trace element systematics. Quaternary Science Review, 26, 441462.

Montagna P., McCulloch M., Taviani M., Trotter J. and Silenzi S. (2009) An improved sampling method for P/Ca as a nutrient proxy. Geochem. Cosmochim. Acta 73, A895.

Morse J. W., Zullig J. J., Bernstein L. D., Millero F. J., Milne P., Mucci A., and Choppin G. R. (1985) Chemistry of calcium carbonate-rich shallow water sediments in the Bahamas. Am. J. Sci. 285, 147-185

Paytan A., Cade-Menun B. J., McLaughlin K., and Faul K. L. (2003) Selective phosphorus regeneration of sinking marine particles: evidence from ${ }^{31} \mathrm{P}-\mathrm{NMR}$. Mar. Chem. 82, 55-70.

Reeder R. J., Nugent M., Lamble G. M., Tait C. D., and Morris D. E. (2000) Uranyl incorporation into calcite and aragonite: XAFS and luminescence studies. Env. Sci. Technol. 34, 638-644.

Rimstidt J. D., Balog A., and Webb J. (1998) Distribution of trace elements between carbonate minerals and aqueous solutions. Geochim. Cosmochim. Acta 62, 1851-1863.

Rothwell W. P., Waugh J. S., and Yesinowski J. P. (1980) High-resolution variable-temperature ${ }^{31} \mathrm{P}$ NMR of solid calcium phosphates. J. Am. Chem. Soc. 102, 2637-2643. 
Sarmiento J. L., Hughes T. M. C., Stouffer R. J., and Manabe S. (1998) Simulated response of the ocean carbon cycle to anthropogenic climate warming, Nature 393, 245-249.

Sawada K., Abdel-Aal N., Sekino H., and Satoh K. (2003) Adsorption of inorganic phosphates and organic polyphosphonate on calcite. J. Chem. Soc. Dalton Trans. 3, 342-347.

Sinclair D. J., and Risk M. J. (2006) A numerical model of trace-element coprecipitation in a physicochemical calcification system: Application to coral biomineralization and traceelement 'vital effects'. Geochim. Cosmochim. Acta 70, 3855-3868.

Shen G.T. and Boyle E.A. (1988) Determination of lead, cadmium, and other trace metals in annually-banded corals. Chem. Geol. 67, 47-62.

Shotyk W., Immenhauserpotthast I., and Vogel H. A. (1995) Determination of Nitrate, Phosphate and Organically Bound Phosphorus in Coral Skeletons by Ion Chromatography. $J$. Chromatogr. A. 706, 209-213.

Teleman A., Richard P., Toivari M., and Penttilla M. (1999) Identification and quantitation of phosphorus metabolites in yeast neutral $\mathrm{pH}$ extracts by nuclear magnetic resonance spectroscopy. Anal. Biochem. 272, 71-79.

Turner G. L., Cade-Menun B. J., Condron L. M., and Newman S. (2005) Extraction of soil organic phosphorus. Talanta 66, 294-306

Turner B. L., Smith K. A., Kirkpatrick R. J., and Oldfield E. (1986) Structure and cation effects on ${ }^{31} \mathrm{P}$ NMR chemical shifts and chemical-shift anisotropies of orthophosphates. J. Magn. Reson. 70, 408-415.

Vandecasteele C. and Block C.B. (1997). Modern methods for trace element determination. John Wiley \& Sons Ltd, West Sussex, England.

Veshtort M. and Griffin R. G. (2006) SPINEVOLUTION: A powerful tool for the simulation of solid and liquid state NMR experiments. J. Mag. Reson. 178, 248-282.

Volk T. and Hoffert M. I. (1985), Ocean carbon pumps: Analysis of relative strengths and efficiencies in ocean-driven atmospheric $\mathrm{CO}_{2}$, in The Carbon Cycle and Atmospheric $\mathrm{CO}_{2}$ : Natural Variations Archean to Present, edited by E. T. Sundquist and W. S. Broecker, pp. 99 - 110, AGU, Washington D. C.

Yesinowski J. P. and Eckert H. (1987) Hydrogen environments in calcium phosphates: ${ }^{1}$ H MAS NMR at high spinning speeds. J. Am. Chem. Soc. 109, 6274-6282.

Zhong S. J. and Mucci A. (1993) Calcite precipitation in seawater using a constant addition technique: A new overall reaction kinetic expression. Geochim. Cosmochim. Acta 57, 1409-1417. 
Table 1: Coral samples studied by ${ }^{31} \mathrm{P}$ NMR, including the location, depth, and dissolved inorganic phosphorus (DIP) concentration of waters in which sample grew at the time of collection. Percentage of the total P contained in apatite $\left(\% \mathrm{P}_{\mathrm{Ap}}\right)$ was estimated by NMR (See text). All corals were live at the time of collection unless otherwise indicated ( $\mathrm{f}=$ fossil). The LA-ICPMS precision (RSD) for the phosphorus concentration is $\sim 6 \%$ (see methods).

\begin{tabular}{|c|c|c|c|c|c|c|c|}
\hline Name & Species & Portion & location & depth (m) & DIP $(\mu \mathrm{M})$ & $\begin{array}{c}{[\mathrm{P}] \text { in solid }} \\
(\mu \mathrm{g} / \mathrm{g})\end{array}$ & $\% \mathbf{P}_{\text {Ap }}$ \\
\hline DD LM99-124 & $\begin{array}{l}\text { Desmophyllum dianthus } \\
\text { (fossil) }\end{array}$ & Septa & Tyrrhenian Sea & $377-411$ & - & $119 \pm 60$ & $35 \pm 5$ \\
\hline DD CHILE CoralA & Desmophyllum dianthus & Theca & Chilean Fjords & 30 & $1.78 \pm 0.36$ & No Data & $41 \pm 7$ \\
\hline DD G16505 S & Desmophyllum dianthus & Septa & Western Pacific & 406 & $1.26 \pm 0.18$ & $202 \pm 55$ & 0 \\
\hline DD G16505 TW & Desmophyllum dianthus & Theca & Western Pacific & 406 & $1.26 \pm 0.18$ & $17 \pm 5$ & $31 \pm 5$ \\
\hline F MAD S & Flabellum sp. & Septa & Madagascar & $800-1000$ & $1.99-2.35$ & $87 \pm 21$ & 0 \\
\hline F MAD TW & Flabellum sp. & Theca & Madagascar & $800-1000$ & $1.99-2.35$ & $55 \pm 11$ & $34 \pm 5$ \\
\hline DD CHILE S & Desmophyllum dianthus & Septa & Chilean Fjords & 30 & $1.78 \pm 0.36$ & $319 \pm 79$ & $8.3 \pm 9$ \\
\hline DD CHILE TW & Desmophyllum dianthus & Theca & Chilean Fjords & 30 & $1.78 \pm 0.36$ & $35 \pm 7.6$ & 0 \\
\hline LP CORAL2 75 & Lophelia pertusa & Theca & Ionian Sea & $828-818$ & $0.26 \pm 0.01$ & $32 \pm 12$ & $15 \pm 3$ \\
\hline LP COBAS 109 & $\begin{array}{l}\text { Lophelia pertusa } \\
\text { (fossil) }\end{array}$ & Theca & Baleares Islands & 366 & - & $106 \pm 19$ & 0 \\
\hline MO CORAL2 75 & Madrepora oculata & Whole coral & Ionian Sea & $828-818$ & $0.26 \pm 0.01$ & No Data & 0 \\
\hline PO FR2004 & Porites sp. & Whole coral & $\begin{array}{c}\text { Fitsroy Reef } \\
\text { (Great Barrier Reef) }\end{array}$ & 5 & $0.12-0.15$ & $36 \pm 11$ & 0 \\
\hline
\end{tabular}


709 Table 2: $\mathrm{P}$ concentration data for select coral samples obtained from solution ICPMS and NMR 710 methods. $[\mathrm{P}]_{\mathrm{Ap}}$ determined from $\% \mathrm{P}_{\mathrm{Ap}}$ values in Table 1 . The solution ICPMS precision (RSD) 711 for the $\mathrm{P} / \mathrm{Ca}$ and $\mathrm{P}$ concentration is $\sim 9.5 \%$ (see methods).

712

\begin{tabular}{|l|c|c|c|c|}
\hline Name & $\begin{array}{c}\mathbf{P} / \mathbf{C a} \\
(\boldsymbol{\mu m o l} / \mathbf{m o l})\end{array}$ & $\begin{array}{c}{[\mathbf{P}]_{\mathbf{I C P M S}}} \\
(\boldsymbol{\mu g} / \mathbf{g})\end{array}$ & $\begin{array}{c}{[\mathbf{P}]_{\text {NMR }}} \\
(\mathbf{\mu g} / \mathbf{g})\end{array}$ & $\begin{array}{c}{[\mathbf{P}]_{\mathbf{A p ~ N M R / I C P M S ~}}} \\
(\boldsymbol{\mu g} / \mathbf{g})\end{array}$ \\
\hline DD G16505 S & $121 \pm 11$ & $38 \pm 4$ & No Data & 0 \\
\hline DD G16505 TW & $68 \pm 6$ & $22 \pm 2$ & No Data & $7 \pm 1$ \\
\hline DD CHILE TW & No Data & No Data & $77 \pm 12$ & No Data \\
\hline DD CHILE TW-ct & No Data & No Data & $35 \pm 5$ & No Data \\
\hline DD CHILE S & $331 \pm 31$ & $118 \pm 11$ & $126 \pm 18$ & $10 \pm 1$ \\
\hline DD CHILE S-ct & $253 \pm 24$ & $83 \pm 8$ & No Data & No Data \\
\hline LP CORAL2 75 & $49 \pm 5$ & $16 \pm 2$ & No Data & $2 \pm 1$ \\
\hline LP COBAS 109 & $374 \pm 36$ & $123 \pm 12$ & $200 \pm 28$ & 0 \\
\hline
\end{tabular}

713 


\section{Figure Captions:}

715 Figure 1: ${ }^{31} \mathrm{P}$ NMR spectra for coral aragonite and aragonite/phosphate coprecipitate samples. a716 f) ${ }^{31} \mathrm{P}\left\{{ }^{1} \mathrm{H}\right\} \mathrm{CP} / \mathrm{MAS}$ NMR spectra of coral septa and thecal wall aragonite a) septa and b) thecal

717 wall of Desmophyllum dianthus (DD CHILE TW) c) septa and d) thecal wall of Flabellum sp. (F

718 MAD TW) e) live collected (LP CORAL2 75) and f) fossil (LP COBAS 109) samples of

719 Lophelia pertusa thecal wall g-h) ${ }^{31} \mathrm{P}\left\{{ }^{1} \mathrm{H}\right\}$ CP/MAS spectra of whole coral samples Madrepora

720 oculata (MO CORAL2 75) and Porites sp. (PO FR2004), respectively. i-j) ${ }^{31} \mathrm{P}\left\{{ }^{1} \mathrm{H}\right\}$ CP/MAS

721 spectra of aragonite/phosphate co-precipitated samples containing i) $306 \mu \mathrm{g} / \mathrm{g}$ and j) $102 \mu \mathrm{g} / \mathrm{g}$ P.

722 All spectra obtained using a spinning rate of $5 \mathrm{kHz}, 2 \mathrm{~ms} \mathrm{CP}$ contact time, and $2 \mathrm{~s}$ pulse delay

723 except h) $10 \mathrm{kHz}$ spinning rate and $120 \mathrm{~s}$ pulse delay and $\mathbf{i}-\mathbf{j}) 2 \mathrm{~ms} \mathrm{CP}$ contact time, $2 \mathrm{~s}$ pulse

724 delay and a spinning rate of $3 \mathrm{kHz}$. Asterisks mark the location of spinning sidebands.

725

726 Figure 2: ${ }^{31} \mathrm{P}$ MAS NMR spectra collected of Desmophyllum dianthus coral septa (DD LM99

727 124) from the Tyrrhenian Sea. a-c) ${ }^{31} \mathrm{P}\left\{{ }^{1} \mathrm{H}\right\}$ CP/MAS NMR spectra collected at a $3 \mathrm{kHz}$ spinning

728 rate and $2 \mathrm{~s}$ pulse delay for 4672 acquisitions using contact times of a) $10 \mathrm{~ms}$, b) $1 \mathrm{~ms}$, and c) 0.2

729 ms. d) ${ }^{31} \mathrm{P}$ SP/MAS NMR spectrum obtained with a $5 \mathrm{kHz}$ spinning rate and $120 \mathrm{~s}$ pulse delay

730 for 819 acquisitions. e) Components of the least squares fit to the spectrum shown in d),

731 vertically offset for clarity.

732

733 Figure 3: ${ }^{31} \mathrm{P}\left\{{ }^{1} \mathrm{H}\right\} \mathrm{CP} / \mathrm{MAS}$ NMR spectra of septa for Desmophyllum dianthus sample DD

734 CHILE S collected using $2 \mathrm{~s}$ pulse delay and $5 \mathrm{~ms} \mathrm{CP}$ contact time at a spinning rate of $3 \mathrm{kHz}$. a)

735 Spectra taken from a sample that was only physically cleaned to remove surface contaminants. 
736 b) Spectra taken from a sample that underwent the chemical treatment outlined by LaVigne et.

737 al. (2008). Asterisks mark the location of spinning sidebands.

739 Figure 4: ${ }^{31} \mathrm{P}$-detected ${ }^{1} \mathrm{H}$ MAS/NMR obtained from summed projections of 2-d ${ }^{31} \mathrm{P}\left\{{ }^{1} \mathrm{H}\right\} \mathrm{CPMG}$

740 HetCor data for a) Desmophyllum dianthus coral sample DD G16505 S and b) synthetic

741 aragonite/phosphate coprecipitate $(520 \mu \mathrm{g} / \mathrm{g} \mathrm{P})$. Both were collected at $2 \mathrm{~ms}$ contact time and 10

$742 \mathrm{kHz}$ spinning rate. Asterisks mark the location of spinning sidebands.

744 Figure 5: ${ }^{31} \mathrm{P}\left\{{ }^{13} \mathrm{C}\right\}$ REDOR NMR spectral sets for ${ }^{13} \mathrm{C}$-enriched aragonite/phosphate

745 coprecipitate collected at a $6 \mathrm{kHz}$ spinning rate and $6.7 \mathrm{~ms}$ dephasing period. SP: Standard

746 SP/REDOR, CP: CP/REDOR with $2 \mathrm{~ms}{ }^{31} \mathrm{P}\left\{{ }^{1} \mathrm{H}\right\}$ CP preparation. a, d) Echo control spectra $\left(S_{0}\right)$

747 b, c) ${ }^{31} \mathrm{P}\left\{{ }^{13} \mathrm{C}\right\}$ REDOR spectra $(S)$. Diamonds denote background signal from rotor and asterisks

748 mark the location of spinning sidebands. $S_{0}, S$ pairs are plotted at the same absolute intensity.

$750 \quad$ Figure 6: Simulated ${ }^{31} \mathrm{P}\left\{{ }^{13} \mathrm{C}\right\}$ REDOR dephasing curve for a ${ }^{31} \mathrm{P}$ surrounded by $6{ }^{13} \mathrm{C}$ at a 751 distance of $3.2 \AA$. Dashed line occurs at the dephasing period where experimental data is 752 reported.

754 Figure 7: ${ }^{19} \mathrm{~F}\left\{{ }^{31} \mathrm{P}\right\}$ REDOR NMR spectra collected for the Flabellum sp. theca sample (F MAD 755 S) collected at a spinning rate of $25 \mathrm{kHz}$, a $100 \mathrm{~s}$ pulse delay, and $1.28 \mathrm{~ms}$ dephasing period for 7561488 acquisitions. Top: ${ }^{19} \mathrm{~F}$ Spin-echo control spectrum (So) Bottom: ${ }^{19} \mathrm{~F}\left\{{ }^{31} \mathrm{P}\right\}$ REDOR spectrum 757 (S). Asterisks mark the location of spinning sidebands. 
759 Figure 8: ${ }^{1} \mathrm{H}\left\{{ }^{31} \mathrm{P}\right\}$ REDOR NMR spectra for a Desmophyllum dianthus (DD CHILE CoralA)

760 sample collected at a spinning rate of $15 \mathrm{kHz}$, pulse delay of $2 \mathrm{~s}$, and dephasing period of $4.4 \mathrm{~ms}$

761 for 62928 aquisitions. Spectra are shown at 5 times vertical exaggeration and truncated. a)

$762{ }^{1} \mathrm{H}\left\{{ }^{31} \mathrm{P}\right\}$ Spin-echo control spectrum $\left(S_{0}\right)$ b) ${ }^{1} \mathrm{H}\left\{{ }^{31} \mathrm{P}\right\}$ REDOR spectrum $(S)$. Dotted line denotes

763 the chemical shift of hydroxylapatite $(0.2 \mathrm{ppm})$ in the Spin-echo control spectrum. Inset:

764 Expanded view of the Spin-echo control spectra over the range of 4 to $-2 \mathrm{ppm}$.

765 
Figure 1:

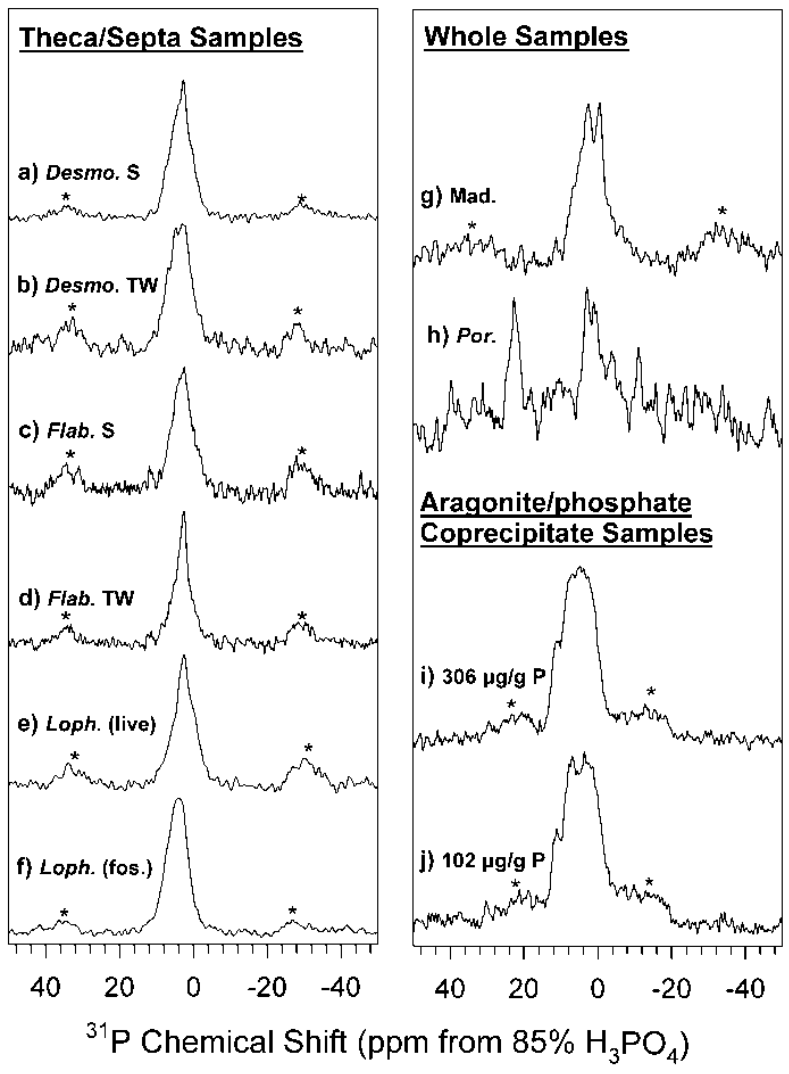

768 
Figure 2:

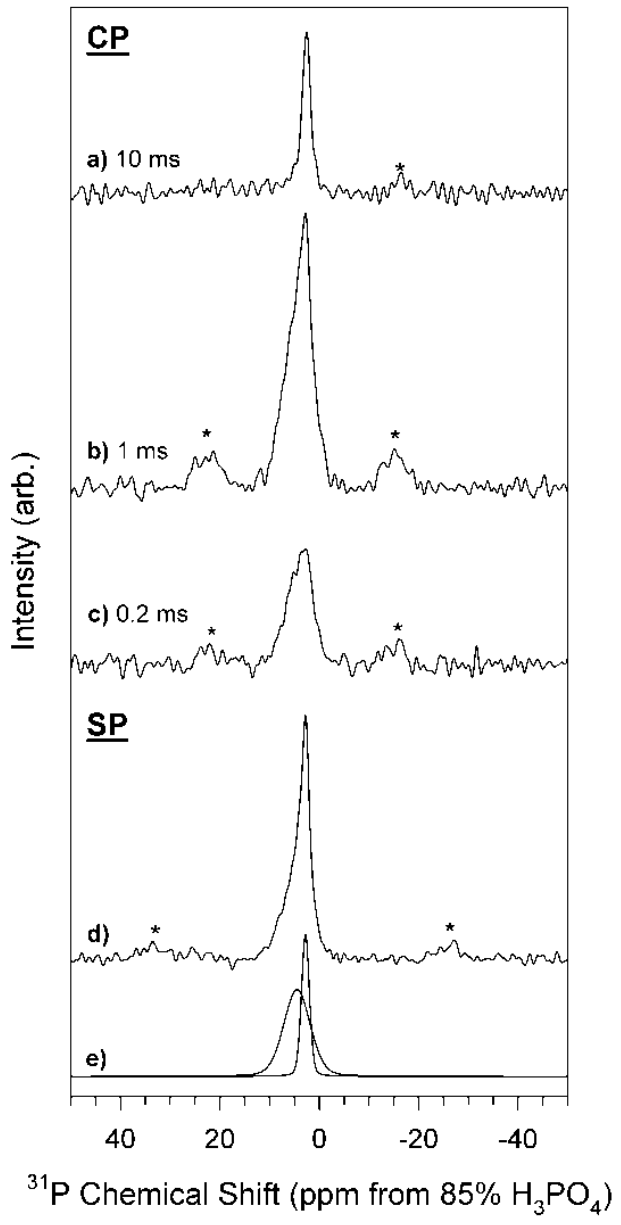

772

773 


\section{Figure 3:}

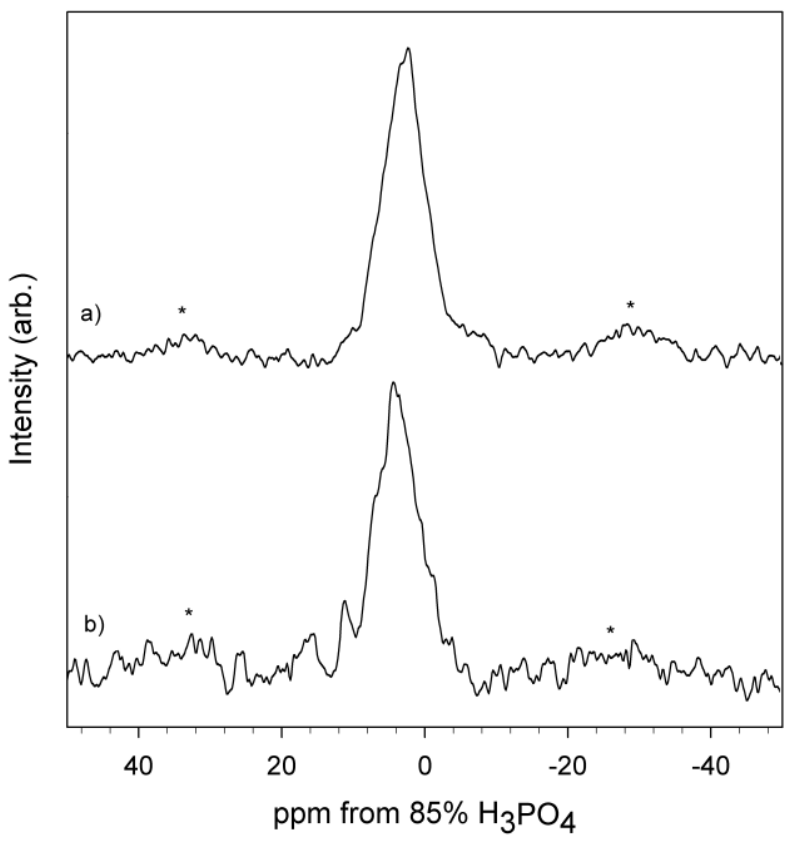

775

776 
777 Figure 4:

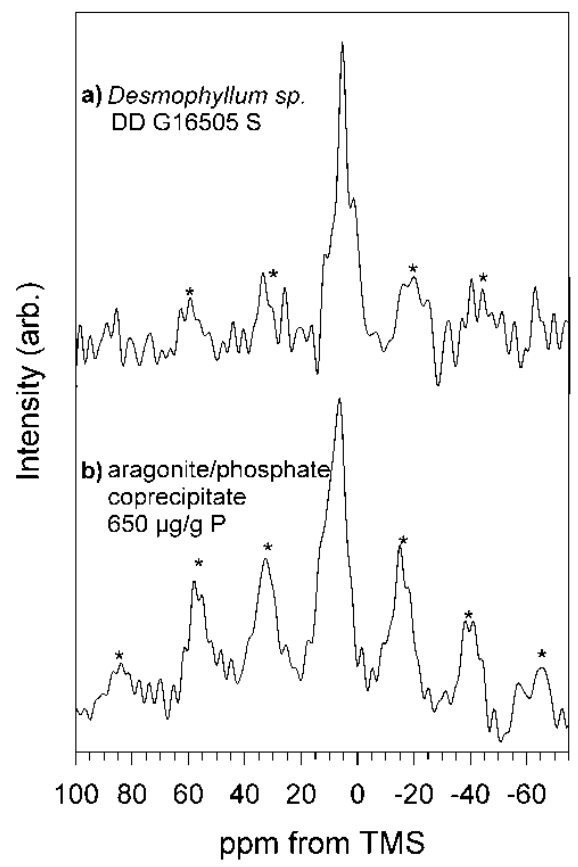

780 


\section{Figure 5:}

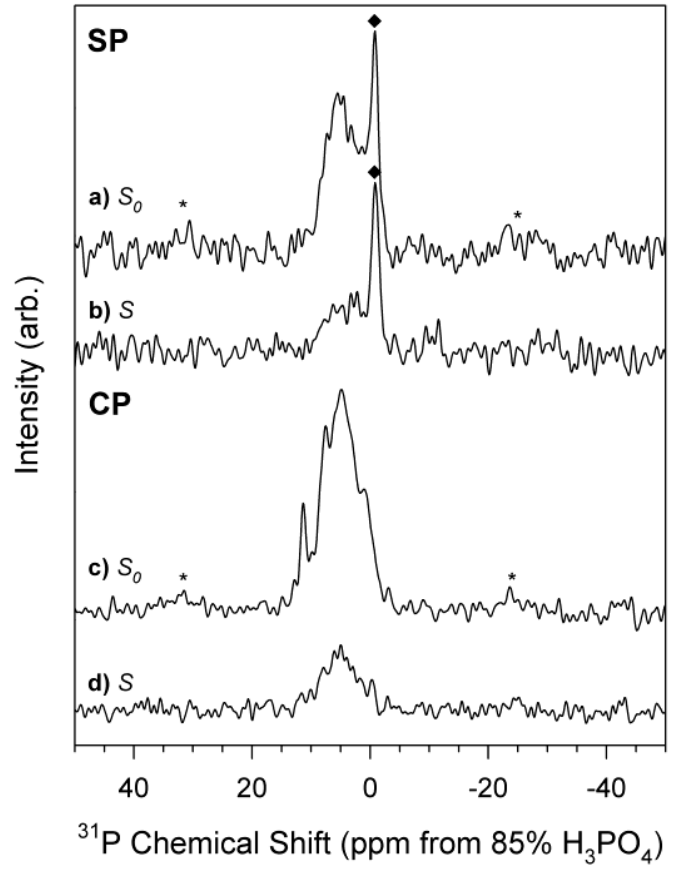

783 


\section{Figure 6:}

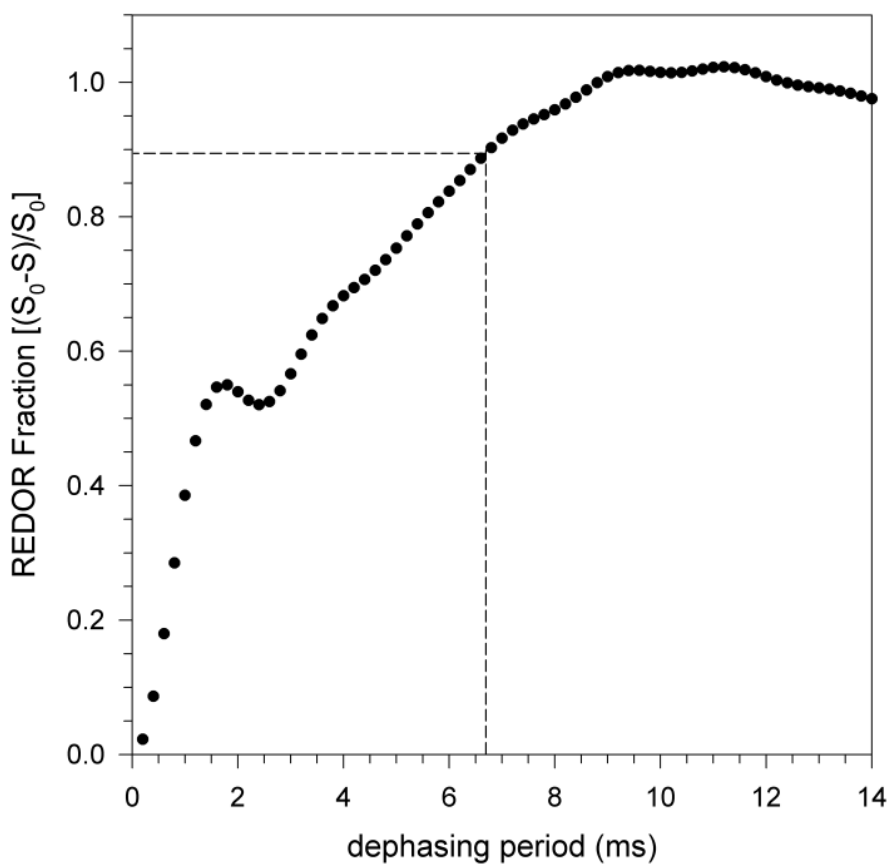

786

787 


\section{$788 \quad$ Figure 7:}

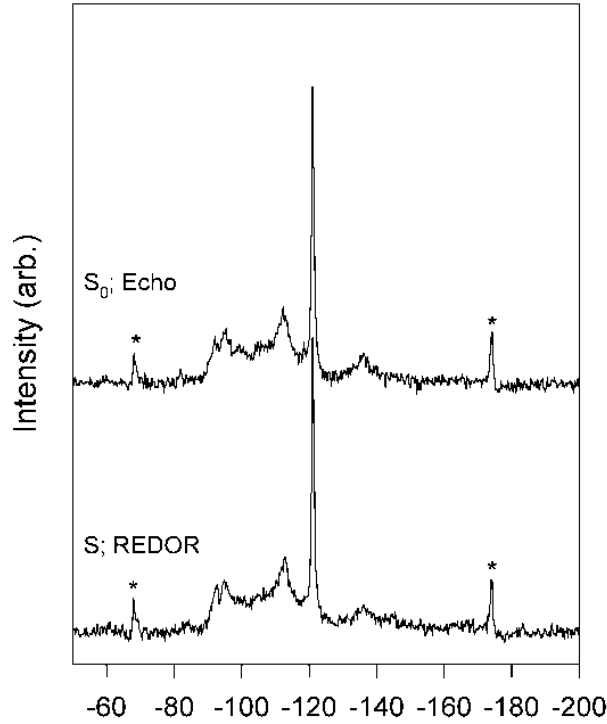

${ }^{19} \mathrm{~F}$ Chemical Shift (ppm from $\mathrm{CFCl}_{3}$ ) 
$791 \quad$ Figure 8:

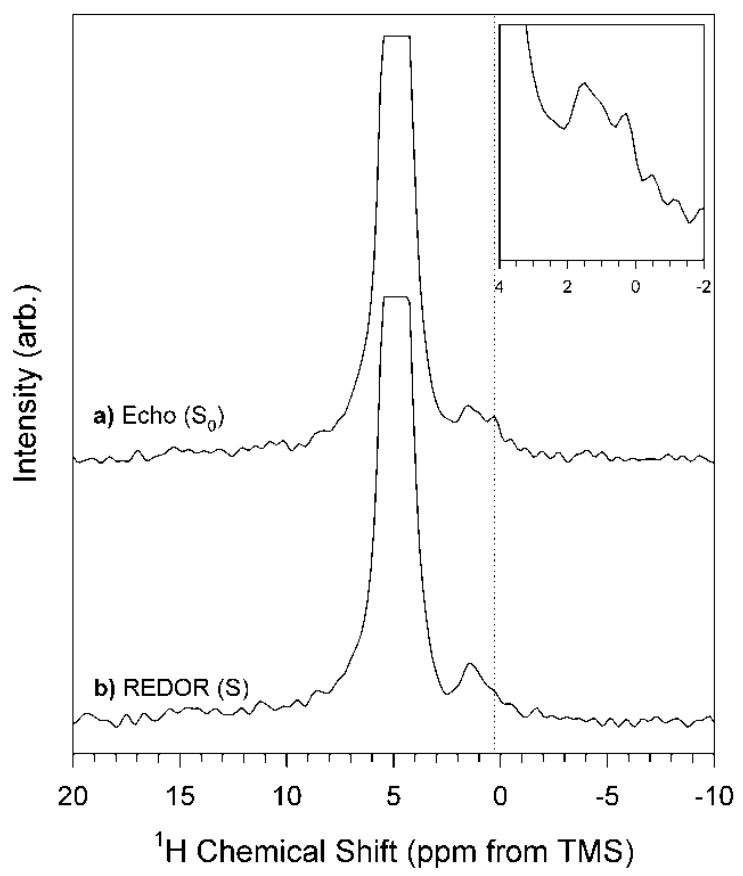

792 